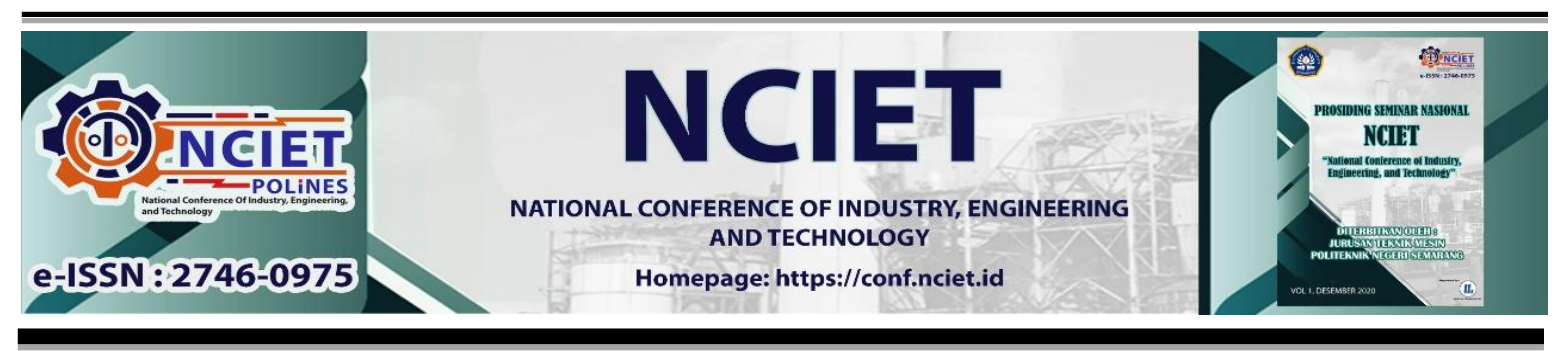

Prosiding Seminar Nasional NCIET Vol.1 (2020) B251-B259

$1^{\text {st }}$ National Conference of Industry, Engineering and Technology 2020,

Semarang, Indonesia.

\title{
PENGARUH PENCAMPURAN BIOETHANOL SEBAGAI BAHAN BAKAR PADA MOTOR BENSIN EMPAT LANGKAH SATU SILINDER
}

\section{Darwin Rio Budi Syaka*, I Wayan Sugita, dan Cahya Raiza Mahendra}

Program Studi Teknik Mesin, Fakultas Teknik, Universitas Negeri Jakarta Jl. R.Mangun Muka Raya, Rawamangun, Kec. Pulo Gadung, Kota Jakarta Timur, Daerah Khusus Ibukota Jakarta 13220

*E-mail: drbsyaka@unj.ac.id

\begin{abstract}
Abstrak
Masalah krisis bbm menunjukkan bahwa cadangan energi fosil indonesia terbatas jumlahnya. Untuk mengatasi kelangkaan bahan bakar dapat dilakukan pencampuran pencampuran bahan bakar dengan bioethanol yang bertujuan untuk mengurangi penggunaan bahan bakar fosil. Salah satu pemanfaatan sumber energi biomassa adalah penggunaan bioethanol karena bioethanol merupakan salah satu bahan bakar alternatif yang ramah lingkungan. Untuk itu penulis melakukan campuran bahan bakar RON 88 dan bioethanol dengan variasi campuran dan RON 88 murni. Metode penelitian yang digunakan pada penelitian ini adalah metode eksperimen yang dilakukan di laboratorium menggunakan motor bensin empat langkah. Variasi putaran mesin yang digunakan yaitu 3000 rpm, $4000 \mathrm{rpm}, 5000 \mathrm{rpm}, 6000 \mathrm{rpm}$ dan $7000 \mathrm{rpm}$. Kemudian masing-masing campuran bahan bakar diuji secara bergantian melalui sepeda motor yang dihubungkan pada dinamometer sasis dan exhaust gas analyzer. Berdasarkan hasil pengujian, penggunaan bioethanol sebagai campuran bahan bakar RON 88 terbukti mampu meningkatkan kinerja torsi dan daya, namun nilai konsumsi bahan bakar campuran bioethanol yang diukur dalam BSFC cenderung lebih irit pada putaran tinggi. selain itu, penggunakan bioethanol juga terbukti dapat mereduksi emisi gas buang sehingga menjadi lebih ramah terhadap lingkungan.
\end{abstract}

Kata Kunci: Bioethanol; Daya; Torsi; BSFC; Emisi Gas Buang.

\section{PENDAHULUAN}

Minyak bumi merupakan sumber energi utama dan salah satu sumber devisa negara. Masalah krisis bbm menunjukkan bahwa cadangan energi fosil yang dimiliki indonesia terbatas jumlahnya. Fakta menunjukkan dimana konsumsi energi terus bertambah meningkat sejalan dengan laju pertumbuhan ekonomi dan pertambahan penduduk diseluruh wilayah Indonesia. Salah satunya yaitu penggunaan konsumsi bahan bakar RON 88 dimana bahan bakar yang banyak digunakan pada kendaraan sepeda motor yang terus meningkat. Terbatasnya minyak bumi menyebabkan perlunya pengembangan energi terbarukan dan konservasi energi yang disebut pengembangan energi hijau. sumber energi 
alternatif bagi manusia adalah energi biomassa. Salah satu pemanfaatan sumber biomassa adalah pembuatan bahan bakar bioethanol (Khaidir, 2016). Bioethanol merupakan bahan bakar dari minyak nabati yang memiliki sifat menyerupai bensin (Wiratmaja, 2010), selain itu juga bioethanol merupakan bahan bakar alternatif yang ramah lingkungan (Harukasari, 2018).

Dari penelitian terdahulu tentang campuran bahan bakar bensin RON 90 dengan bioethanol pernah dilakukan oleh Arief Abi Karomi, dengan komposisi E0 (RON 90 murni), E5, E10, E15, E20 dan E25. Hasil penelitian menunjukkan bahwa daya dan torsi terbaik yang dihasilkan oleh bahan bakar campuran E10 pada putaran mesin $3000 \mathrm{rpm}$ dan 4000 rpm, sedangkan E20 daya dan torsi terbaik dihasilkan pada putaran mesin 2000 rpm, serta komposisi E25 daya dan torsi terbaik dihasilkan pada putaran mesin $5000 \mathrm{rpm}$ (Karomi, 2016). Kemudian penelitian lain, yang juga menggunakan campuran bahan bakar bensin RON 90 dengan bioethanol pada E10, E20 dan E30, memperoleh hasil bahwa peningkatan kadar bioethanol meningkatkan daya namun torsi cenderung menurun, sedangkan penambahan bioethanol juga dapat menghemat bahan bakar dan menurunkan kadar emisi gas buang (Prasetyo \& Effendy, 2018). Selain itu, Yuda Helmi dengan komposisi E0 (RON 90 murni), E5 (Etanol 5\% dan 95\% RON 90), E10 dan E15. Berdasarkan hasil pengujian, menunjukkan bahwa, peningkatan torsi dan daya engkol terbaik didapatkan saat menggunakan bahan bakar campuran pertalite dan bioetanol $15 \%$ (E15) pada putaran mesin $2500 \mathrm{rpm}$. Pada pengujian emisi gas buang, penurunan kadar CO dan $\mathrm{HC}$ terbaik diperoleh pada saat menggunakan bahan bakar campuran pertalite dan bioetanol 15\% (E15), yaitu sebesar 48,46\%, dan 47,71\% (Helmi, 2018). Pada penelitian campuran bioethanol dengan RON92 torsi yang dihasilkan semakin meningkat seiring dengan peningkatan campuran namun untuk daya menurun pada campuran diatas $30 \%$ (Susilo \& Sabudin, 2018). Adapun untuk penelitian yang membandingkan campuran bioethanol dengan RON88, RON90 dan RON92 baru pada pengujian kinerja torsi, daya dan konsumsi bahan bakar, dan belum ada data pengaruh campuran pada emisi gas buang (Fajar Laksono, 2016).

Dari penelitian yang telah dilakukan seperti di atas, maka dapat disimpulkan bahwa penambahan bioethanol pada bahan bakar menimbulkan dampak yang positif dari sisi peningkatan prestasi mesin (torsi, daya engkol dan konsumsi bahan bakar), juga penurunan emisi gas buang. Oleh karenanya, penelitian ini penting dilakukan untuk mengurangi dampak penggunaan bahan bakar premium (RON 88) secara terus menerus yang massif 
digunakan pada sepeda motor serta mengurangi emisi gas buang yang tinggi yang dihasilkan dari kendaraan dan menggantikannya dengan bahan bakar alternatif serta memperoleh pengaruh campuran bioethanol dengan premium terhadap daya, torsi dan konsumsi bahan bakar spesifik motor bensin 4 langkah .

\section{METODE PENELITIAN}

Alat dan bahan yang digunakan dalam penelitian ini yaitu :

1. Bahan bakar RON 88

6. Tool set

2. Bioethanol

7. Tabung ukur

3. Motor 4 langkah SOHC

8. Gelas ukur

4. Computerized dynamometer

9. Buret

5. Exhaust gas analyzer

10. Stopwatch

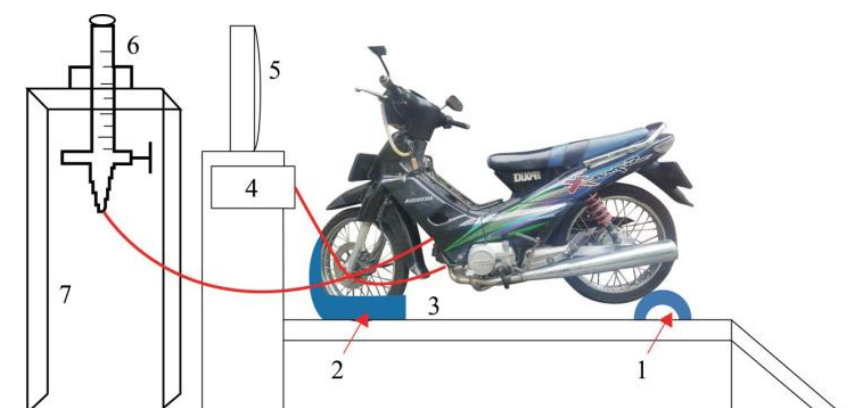

Gambar 1. Skema Pengujian Daya, Torsi dan BSFC

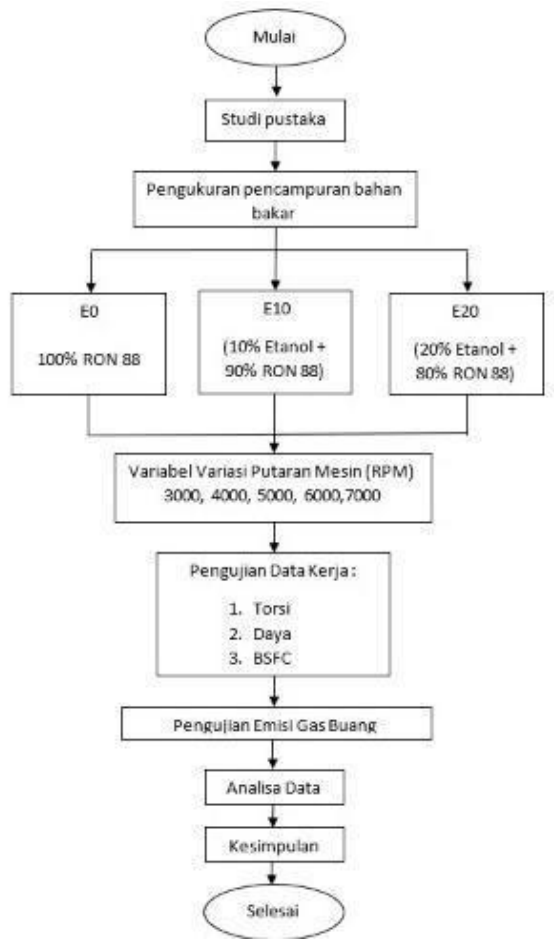

Gambar 2. Diagram Alir Penelitian 
Hal yang dipersiapkan sebelum melakukan pengujian yaitu mengecek fisik kendaraan serta perlu dilakukan tune-up terlebih dahulu agar sesuai dengan spesifikasi standar dan motor dalam keadaan maksimal dan prima. Metode yang digunakan dalam penelitian ini adalah metode pengujian performa mesin sepeda motor (computerized dynamometer). Pengujian dilakukan dengan memposisikan sepeda motor pada alat computerized dynamometer, selanjutnya mesin dihidupkan dan diuji dalam varian putaran mesin (rpm) dan hasil pengujian computerized dynamometer yang terbaca pada layar monitor. Pengujian ini dilakukan tiga kali dengan variasi campuran bahan bakar RON 88 dan bioethanol yang berbeda.

\section{HASIL DAN PEMBAHASAN}

Hasil data daya, torsi, konsumsi bahan bakar spesifik (BSFC) dan emisi gas buang motor bensin 4 langkah sepeda motor $100 \mathrm{cc}$ didapatkan dari pengujian langsung menggunakan dinamometer sasis. Dari hasil pengujian torsi motor menggunakan dynamometer dengan tiga sampel bahan bakar yaitu E0, E10, dan E20, maka didapatkan angka perbandingan dari setiap variasi putaran mesin untuk masing-masing bahan bakar sebagai berikut:

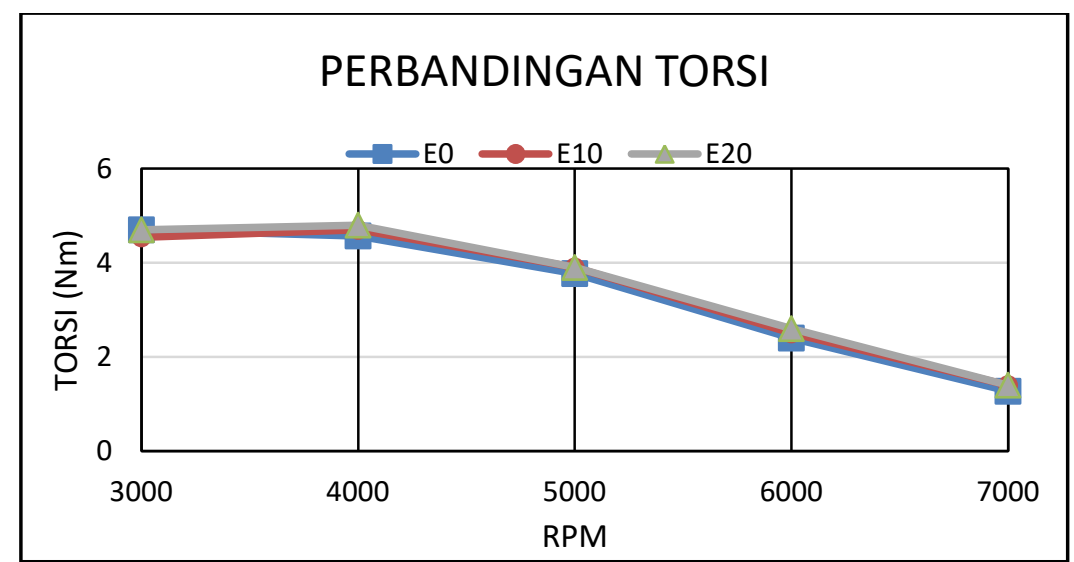

Gambar 3. Perbandingan Torsi

Dapat dilihat pada gambar 3, torsi maksimal yang dihasilkan motor menggunakan bahan bakar E20 lebih besar dibanding E10 dan E0 meskipun terlihat tampak hal ini karena berkaitan dengan karakteristik valve timing diagram engine ini yang memiliki efisiensi volumetrik yang sama. 


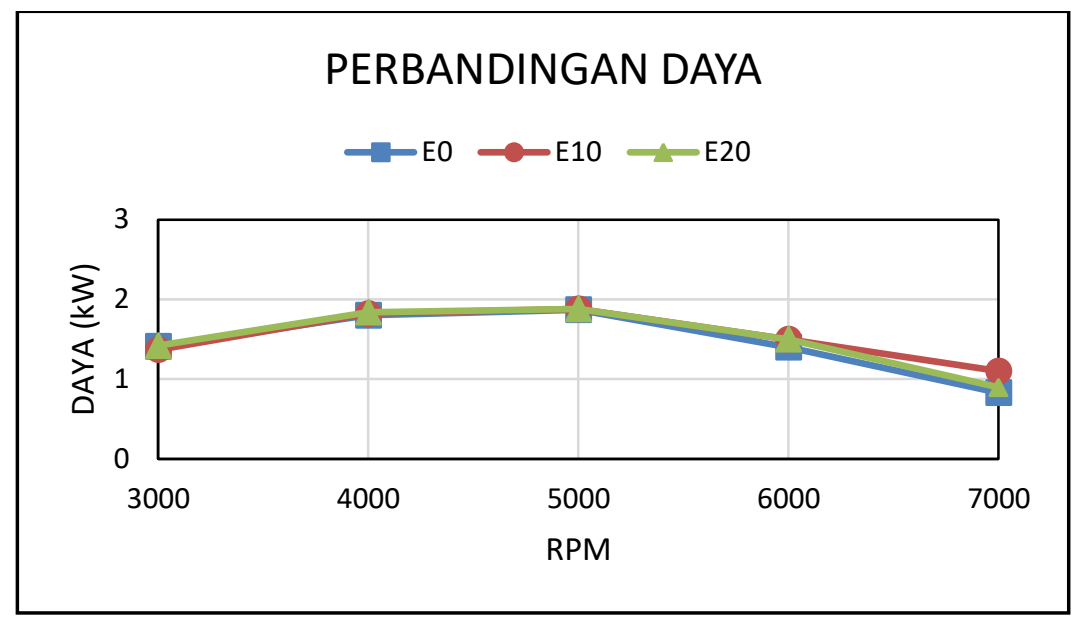

Gambar 4. Perbandingan Daya

Dapat dilihat daya maksimal pada gambar 4, daya yang dihasilkan motor menggunakan bahan bakar campuran E10 dan E20 lebih besar dibandingkan bahan bakar RON 88 (E0) . Hal ini berhubungan dengan nilai torsi dari masing-masing bahan bakar. Sesuai dengan rumus $\mathrm{P}=\frac{2 \pi n \mathrm{~T}}{75 \times 60}$, nilai daya dipengaruhi oleh torsi dan putaran mesin, jika torsi meningkat maka daya akan meningkat, jika torsi menurun maka daya akan menurun atau torsi menurun maka daya akan meningkat itu dikarenakan putaran mesin yang semakin tinggi. Hal ini juga berhubungan dengan nilai AFR dari masing masing bahan bakar.

Dari hasil pengujian konsumsi bahan bakar bersamaan dengan pengujian torsi dan daya di atas dynamometer dengan tiga sampel bahan bakar yaitu E0, E10, dan E20, kemudian data konsumsi diformulasikan dengan persamaan $\mathrm{BSFC}=\frac{m}{B H P}$ didapatkan angka perbandingan BSFC setiap putaran mesin untuk masing-masing bahan bakar sebagai berikut:

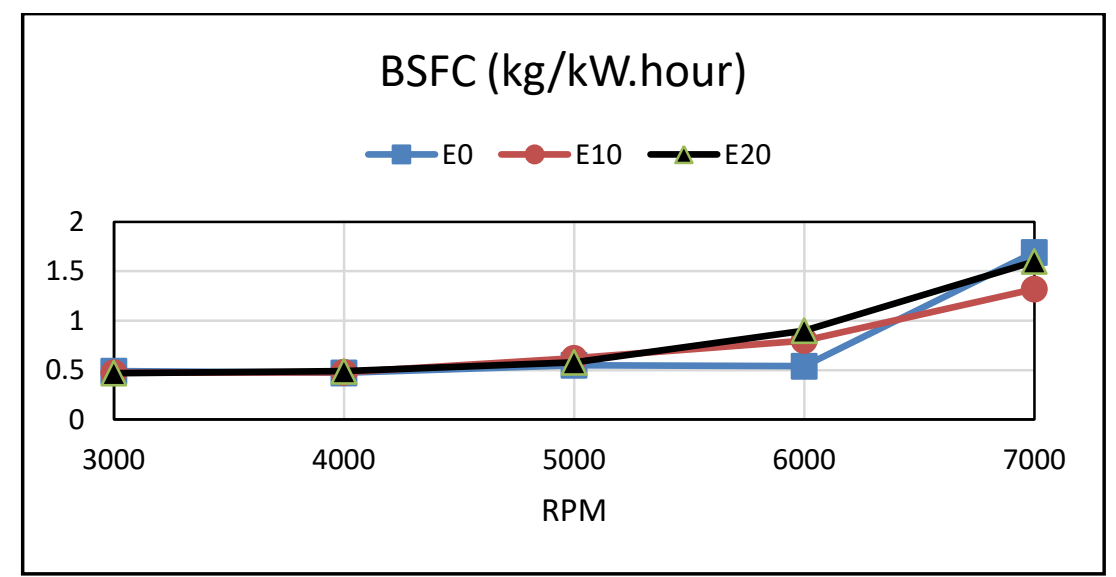

Gambar 5. Perbandingan BSFC 
Berdasarkan gambar 5, alur garis dari ketiga bahan bakar terlihat sama dari putaran mesin 3000 rpm hingga 4000 rpm. Nilai BSFC bahan bakar RON 88 (E0) terlihat tidak stabil pada putaran mesin $5000 \mathrm{rpm}$ hingga $7000 \mathrm{rpm}$ dibandingkan dengan bahan bakar E10 dan E20 dengan kenaikan yang stabil di setiap RPM-nya. Ini menandakan bahwa bahan bakar E10 dan E20 memiliki tingkat pembakaran yang baik dibandingkan dengan bahan bakar RON 88 (E0) sehingga bahan bakar RON 88 banyak yang terbuang dan mengakibatkan lebih boros karena tidak terbakar secara sempurna. Nilai minimal BSFC yang tercatat sebesar $0.471 \mathrm{~kg} / \mathrm{kW}$.hour untuk bahan bakar E20 pada putaran mesin 3000 rpm. Sedangkan untuk bahan bakar E10 yaitu sebesar $0.474 \mathrm{~kg} / \mathrm{kW}$.hour dengan putaran mesin yang sama di $3000 \mathrm{rpm}$ dan persentase penurunan sebesar $0.63 \%$ dari E20. kemudian untuk bahan bakar RON 88 yaitu $0.472 \mathrm{~kg} / \mathrm{kW}$.hour pada putaran $4000 \mathrm{rpm}$ dan persentase penurunan sebesar $0.42 \%$ dari E10.

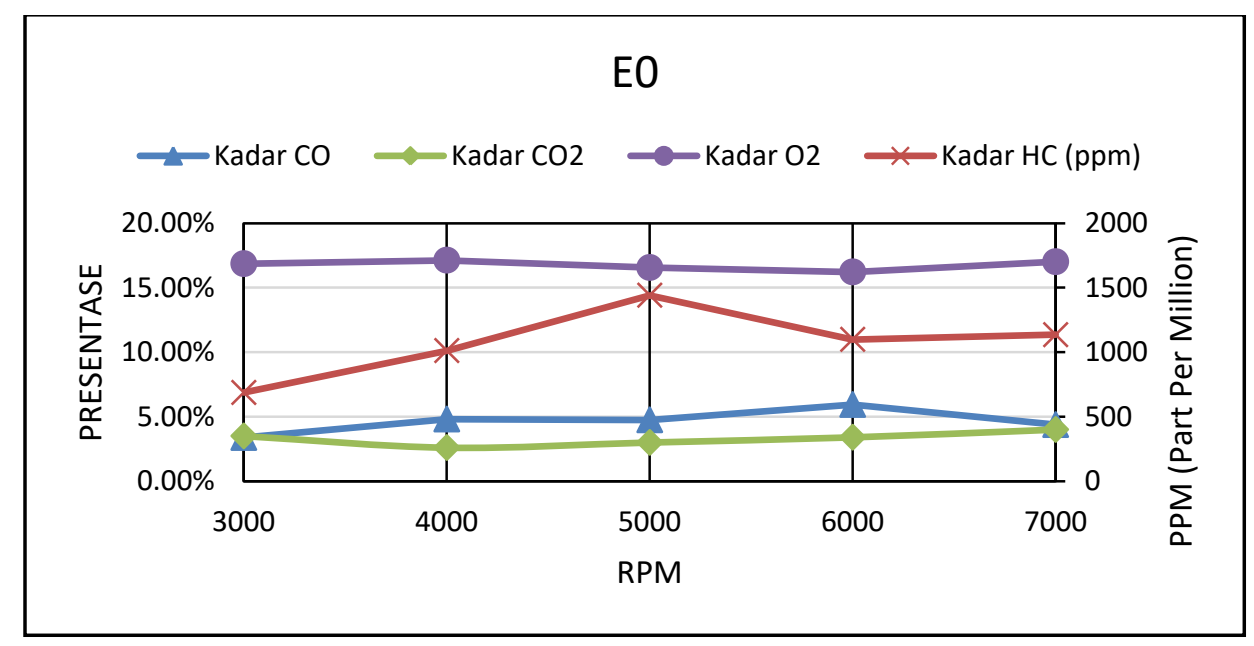

Gambar 6. Perbandingan Emisi E0

Dapat dilihat pada gambar 6 mulai dari kadar HC, terlihat pada grafik HC yang fluktuatif, Naik turunnya kadar HC ini disebabkan oleh reaksi pembakaran apabila HC + $\mathrm{O}_{2} \rightarrow \mathrm{CO}+\mathrm{H}_{2} \mathrm{O}+\mathrm{HC}$ yang mana bila udara kurang dan $\mathrm{HC}$ berlebih serta faktor bensin yang tidak terbakar dan kurangnya campuran udara-bahan bakar yang masuk kedalam ruang silinder sehingga pembakaran tidak sempurna. Selanjutnya pada kadar CO yang tinggi dilihat dari putaran mesin yang fluktuatif, faktor CO yang tinggi ini disebabkan oleh reaksi pembakaran $\mathrm{HC}+\mathrm{O} 2 \rightarrow \mathrm{CO}+\mathrm{H}_{2} \mathrm{O}$ dimana udara yang kurang akan menghasilkan gas CO serta AFR yang rendah dan kurangnya oksigen untuk menghasilkan pembakaran yang tuntas dan sempurna. pada kadar $\mathrm{CO}_{2}$ yang rendah dibandingkan dengan kadar $\mathrm{CO}$ yang tinggi hal ini berdasarkan teori pembakaran dimana apabila kadar CO tinggi maka kadar $\mathrm{CO}_{2}$ rendah begitupun sebaliknya, Hal ini disebabkan oleh AFR pada setiap putaran 
mesin yang cenderung menurun. Selanjutnya kadar $\mathrm{O}_{2}$, Kadar oksigen yang tinggi ini disebabkan oleh udara yang berlebih dimana sesuai teori reaksi pembakaran $\mathrm{HC}+\mathrm{O}_{2} \rightarrow$ $\mathrm{CO}_{2}+\mathrm{H}_{2} \mathrm{O}+\mathrm{O}_{2}$ dan faktor AFR yang terlalu kurus sehingga jumlah udara yang masuk keruang bakar ini berbanding dengan jumlah bensin terbakar didalam silinder.

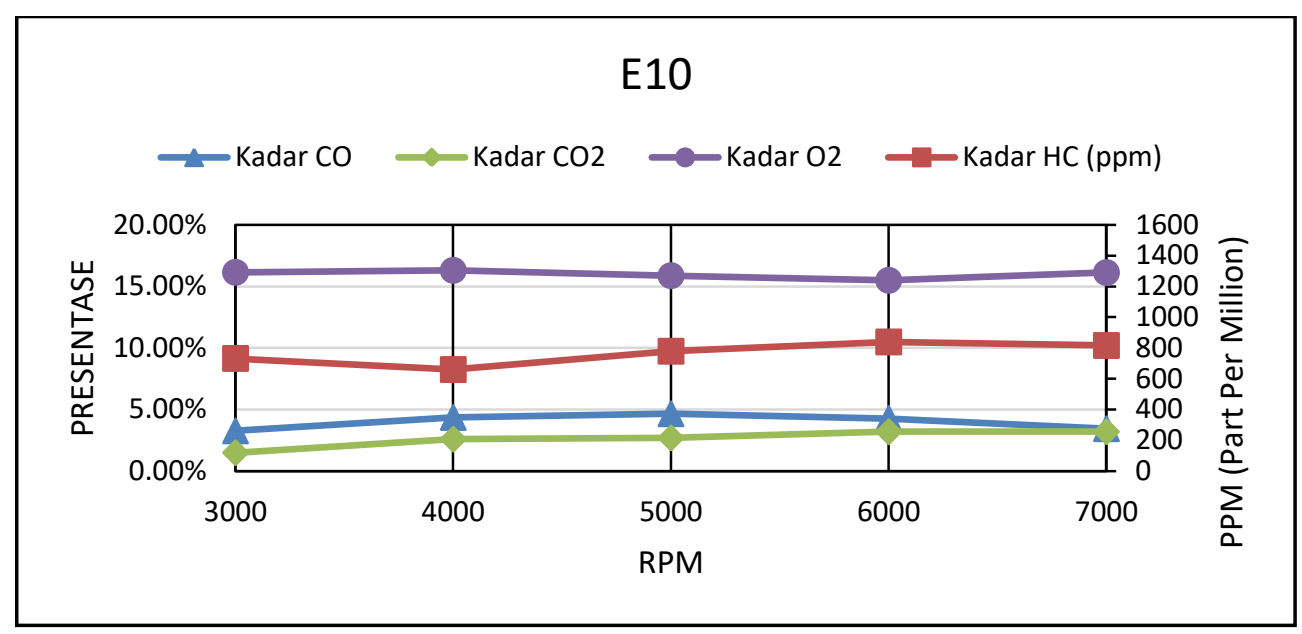

Gambar 7. Perbandingan Emisi E10

Emisi gas buang bahan bakar E10 yaitu dapat dilihat pada gambar 7 mulai dari kadar $\mathrm{HC}$, nilai ppm terlihat stabil dan menurun dibandingkan bahan bakar E0 hal ini disebabkan oleh reaksi pembakaran apabila $\mathrm{HC}+\mathrm{O}_{2} \rightarrow \mathrm{CO}+\mathrm{H}_{2} \mathrm{O}+\mathrm{HC}$ yang mana udara kurang dan HC berlebih serta pengaruh volume campuran udara-bahan bakar yang cenderung berkurang pada tiap rpmnya seiring dengan naiknya putaran rpm mesin. Selanjutnya pada kadar CO tinggi yang fluktuatif Turunnya kadar CO ini disebabkan oleh reaksi pembakaran dimana udara yang masuk ke silinder kurang dan putaran mesin. Kemudian Emisi $\mathrm{CO}_{2}$ merupakan gas hasil sisa pembakaran yang banyak terdapat di udara, gas $\mathrm{CO}_{2}$ terbentuk akibat pembakaran yang sempurna. Lalu terlihat pada grafik kadar $\mathrm{CO}_{2}$ yang rendah dibandingkan dengan kadar $\mathrm{CO}$ yang tinggi hal ini berdasarkan teori pembakaran dimana apabila kadar $\mathrm{CO}$ tinggi maka kadar $\mathrm{CO}_{2}$ rendah begitupun sebaliknya, dapat dilihat pada grafik $\mathrm{CO}_{2}$ dimana kadar $\mathrm{CO}_{2}$ E10 cenderung lebih stabil dibandingkan bahan bakar E0. Pada kadar $\mathrm{O}_{2}$ Hal ini disebabkan karena dalam bioethanol sudah mengandung oksigen sehingga mampu terbakar lebih sempurna. Selanjutnya pada kadar $\mathrm{O}_{2}$ terlihat grafik yang fluktuatif. Secara teoritis bioethanol merupakan salah satu oksigenat yang baik sehingga penambahan bioethanol ke dalam bensin dapat meningkatkan kandungan oksigen. 


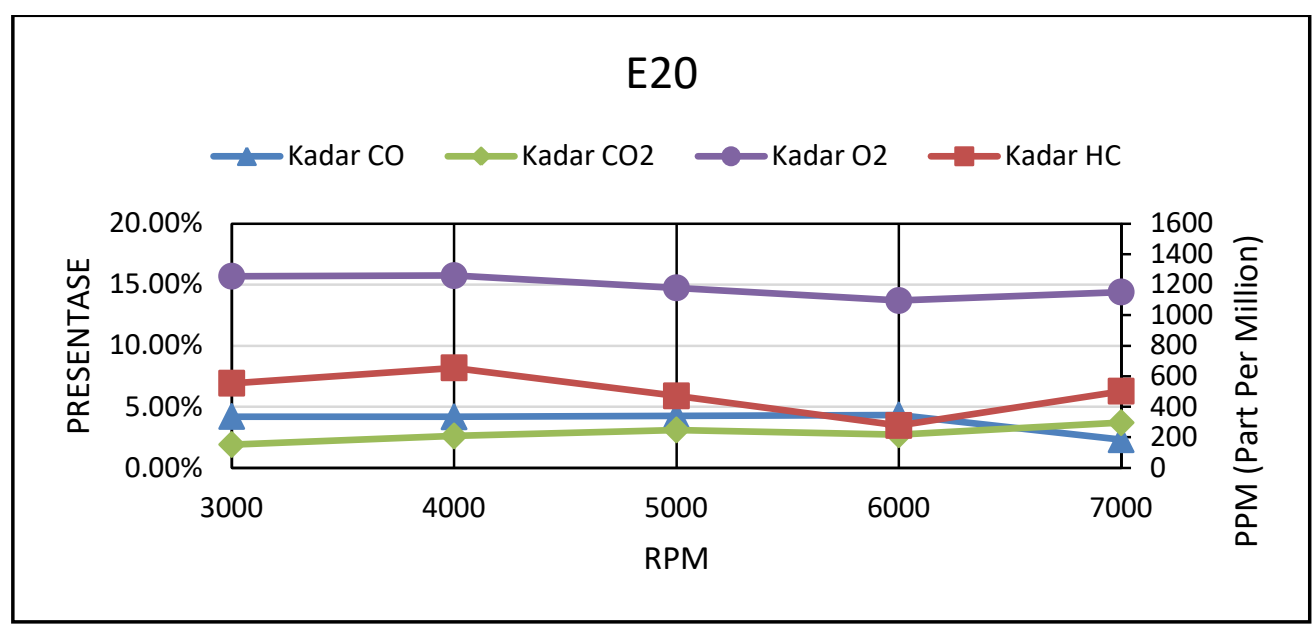

Gambar 8. Perbandingan Emisi E20

Dapat dilihat pada gambar 8 mulai dari kadar HC, terlihat pada nilai ppm tiap rpm jauh lebih kecil dibandingkan dengan bahan bakar E10 dan E0 ini menandakan bahwa campuran udara-bahan bakar yang terbakar didalam silinder semakin sempurna dan disebabkan karena nilai penguapan yang cukup rendah sehingga pada saat pembakaran HC terurai oleh oksigen. Selanjutnya pada kadar CO tinggi yang fluktuatif terlihat Turunnya kadar CO ini disebabkan oleh campuran udara-bahan bakar dan putaran mesin. Kemudian Emisi $\mathrm{CO}_{2}$ merupakan gas hasil sisa pembakaran yang banyak terdapat di udara, gas $\mathrm{CO}_{2}$ terbentuk akibat pembakaran yang sempurna. Lalu terlihat pada grafik kadar $\mathrm{CO}_{2}$ yang rendah dibandingkan dengan kadar CO yang tinggi hal ini berdasarkan teori pembakaran dimana apabila kadar $\mathrm{CO}$ tinggi maka kadar $\mathrm{CO}_{2}$ rendah begitupun sebaliknya, dapat dilihat pada grafik $\mathrm{CO}_{2}$ dimana kadar $\mathrm{CO}_{2}$ E20 cenderung lebih stabil dibandingkan bahan bakar E0. Hal ini disebabkan karena dalam bioethanol sudah mengandung oksigen sehingga mampu terbakar lebih sempurna. Selanjutnya pada kadar $\mathrm{O}_{2}$ terlihat grafik yang fluktuatif. Secara teoritis bioethanol merupakan salah satu oksigenat yang baik sehingga penambahan bioethanol kedalam bensin dapat meningkatkan kandungan oksigen.

\section{KESIMPULAN}

Berdasarkan hasil penelitian, maka dapat ditarik beberapa kesimpulan antara lain :

1. Pengaruh penambahan bioethanol pada motor bensin empat langkah terbukti mampu meningkatkan torsi dan daya, semakin tinggi kadar bioethanol maka torsi dan daya semakin meningkat

2. Nilai BSFC pada bahan bakar E10 cenderung boros pada putaran 3000 sampai $6000 \mathrm{rpm}$ dan lebih irit di putaran $7000 \mathrm{rpm}$. Nilai BSFC pada bahan bakar E20 
cenderung boros pada putaran 4000 sampai $6000 \mathrm{rpm}$ namun mencatat nilai minimal yang lebih irit di putaran $3000 \mathrm{rpm}$ dan $7000 \mathrm{rpm}$ dibanding bahan bakar RON 88.

3. Pengaruh emisi gas buang yang menggunakan bahan bakar bioethanol mencatatkan hasil HC yang jauh lebih rendah dibandingkan bahan bakar RON 88, Peningkatan nilai $\mathrm{CO}_{2}$ yang lebih baik dibandingkan bahan bakar RON 88 dan penurunan kadar $\mathrm{O}_{2}$, Hal ini menunjukkan bahwa penambahan bioethanol pada bahan bakar terbukti mampu menghasilkan emisi gas buang yang ramah lingkungan dibandingkan bahan bakar RON 88.

\section{DAFTAR PUSTAKA}

Fajar Laksono, D. (2016). Pengaruh Campuran Bioethanol dengan Premium, Pertalite, dan Pertamax terhadap performa mesin sepeda motor 4 Langkah. Universitas Negeri Semarang.

Harukasari, A. (2018). Bioetanol Sebagai Bahan Bakar Alternatif. (May).

Helmi, Y. (2018). Pengaruh Variasi Campuran Bahan Bakar Pertalite dan Bioethanol Terhadap Prestasi Mesin dan Emisi Gas Buang Mesin Bensin 4-Langkah Tecquipment TD201. Universitas Lampung.

Karomi, A. A. (2016). Pengaruh Penambahan Etanol dalam Bahan Bakar Pertalite Terhadap Performa dan Emisi Gas Buang Mesin 4 Silinder. Universitas Negeri Semarang.

Khaidir. (2016). Pengolahan limbah pertanian sebagai bahan bakar alternatif. Jurnal Agrium, 13(2), 63-68.

Prasetyo, I., \& Effendy, M. (2018). Bioetanol Dari Bahan Baku Singkong Sebagai Bahan. 19(2), 43-54.

Susilo, S. H., \& Sabudin, A. M. (2018). Pengaruh Campuran Bioetanol-Pertamax 92 terhadap Kinerja Motor Otto. 01(02), 21-26.

Wiratmaja, I. (2010). Pengujian Karakteristik Fisika Biogasoline Sebagai Bahan Bakar Alternatif Pengganti Bensin Murni. Jurnal Energi Dan Manufaktur, 4(2). 